\title{
Post-Covid Tourism, A Consensual Re-Reading of the Economic Outlook Application of the Delphi Method to "Morocco" Destination
}

\section{Abstract}

The unprecedented health crisis of COVID-19 has deeply affected the tourism industry around the world. As a direct consequence, more than three billion potential tourists have been confined (Donthu \& Gustafsson, 2020) and the other actors (hosting companies, restaurateurs, transporters, etc.) are looking to understand the future of this tourist demand and its effects on their tourist destination. They are currently searching for answers to situate themselves between the multitude of potential possibilities and the uncertain and changing perspectives.

Indeed, between adaptation and resilience, it is evident that there is a latent demand for tourism stays, ready to manifest after these long periods of confinement. However, the behavior of this tourist demand remains complex and highly dependent on the health conditions imposed by the pandemic, on the freedom of travel and on the perception of health risks by the key actors of tourist destinations.

In this context, a literature review allows to define three key scenarios for tomorrow's tourism, namely the growth of local tourism or 'domestic tourism' (Blanc, 2020; Donthu \& Gustafsson, 2020; Zenker \& Kock, 2020), the emergence of a 'Stop and Go' tourism that can adapt continuously to pandemic situation evolution (Jiricka-Pürrer et al., 2020; Ŭ̆ur \& Akbryı, 2020). Finally, the development of tourism internalizing the health risk.

Therefore, the definition of a Moroccan tourism scenario needs a depth review of the current situation and a re-reading of the "wait and see" outlook for the onset of the health crisis. Since the pandemic appears, behaviors of the tourism stakeholders is already evolving in the short and medium run. Consequently, the re-reading of outlook must be a consensual process entrusted to tourism experts.

To this end, we have suggested the use of the Delphi process. This technique aims to ensure a convergence of opinions on forward-looking issues, such as demand for sustainable tourism (Choi $\mathcal{E}$ Sirakaya, 2006) and predictions on tourist destination attractiveness (Lee E Hsieh, 2016; Miller, 2001; Torres-Delgado \& Palomeque, 2014). Thus, the Delphi survey takes place in a variety of rounds, taking into account the opinions convergence of confirmed tourism expert's panel, namely provincial tourism delegates, members of tourism associations, specialists in sustainable tourism, researchers in tourism, etc.

Thus, Delphi survey results will make possible to prevail a post-COVID tourism scenario and to forecast the key actors' reactions, facing the evolution of this global pandemic.

\section{Introduction}

The health crisis of COVID-19 has heavily affected tourism activities and as a result, tourism demand will inevitably change and adopt behaviors that are difficult to anticipate (Blanc, 2020).

Today, it is strategic to "draw" horizons that can be able to orient the key actors' actions and planning to meet the strong latent demand of Post-COVID. Consequently, understanding the behavior of this tourism demand will allow looking for new ways of visiting destinations and fulfill this need for escape.

Therefore, for a country like Morocco, very dependent on tourism activity, predicting a scenario requires a detailed analysis of the current situation. In addition, it is important to analyze the "wait 
and see" outlook for the onset of the health crisis, because the pandemic appears to be taking place in the short and medium term and the conduct of the tourism stakeholders is already changing. Consequently, the re-reading of viewpoints must be a consensual process, entrusted to tourism experts.

To this end, this paper suggests to use the Delphi method to ensure a convergence of opinions on a scenario forecasting the future of tourism demand, during and after the health crisis of COVID19 , and to prevail one scenario among those identified in the literature review.

\section{Literature Review}

The recent literature review on COVID-19 tourism impacts allows to define three key scenarios for tomorrow's tourism, namely the growth of local tourism or 'domestic tourism' (Blanc, 2020; Donthu \& Gustafsson, 2020; Zenker \& Kock, 2020), the emergence of a 'Stop and Go' tourism that can adapt continuously to pandemic situation evolution (Jiricka-Pürrer et al., 2020; Uğur \& Akbiy1, 2020). Finally, the scenario is to predict the development of tourism internalizing the health risk.

\subsection{Scenario ${ }^{\circ} 1$ : "Rise of a Domestic Tourism"}

This crisis seems to be projected over the medium run; Moreover, some countries remain closed for the long run. The dynamism of domestic tourism under health control remains the only possible solution to save the tourism sector.

The need to escape is pressing for many tourists, but health constraints dictate the ways of visiting a destination. This need cannot be "oppressed" for a long time, but it will be satisfied by alternatives of proximity visits and small pleasure of escape close of visitor's home.

This local or domestic tourism offers adapted packages, based mainly on bars and restaurants, sports, cultural and leisure activities (day and night) (Blanc, 2020).

The health crisis also shows the capacity of soft forms of tourism to absorb tourist demand abroad. For example, rural tourism is renewing itself by integrating new sanitary requirements, and standards of comfort.

Thus, we are going to witness a new situation in the tourist geography that is being recomposed again, with the emergence of rural destinations, mountains and valleys, far from the crowds. However, these territories, such as natural parks, do not have sufficient reception capacities to meet the sharply increasing demand.

\subsection{Scenario ${ }^{\circ} 2$ : "Stop and GO" Tourism}

In this very volatile health crisis, tourism demand is able to adapt systematically and continuously to the epidemic evolution (Blanc, 2020; Duarte Alonso et al., 2020; Kock et al., 2020).

In this sense, an increase in infected cases in a tourism destination and the tightening of health measures lead to the postponement of tourist demand. On the contrary, controlling the epidemic in another destinations and reducing health restrictions measures will stimulate tourism demand.

Therefore, this scenario, called "Stop and GO" envisages an adaptable behavior of tourist demand following the disease situation evolution. However, this scenario is more focused on the short and medium run (Zenker \& Kock, 2020).

\subsection{Scenario ${ }^{\circ} 3$ : "Development of Tourism Internalizing the Health Risk"}

The coronavirus pandemic COVID-19 is above all, a humanitarian crisis that has consequences for people's lives. Confinement and fear of contamination generate a psychological pressure on the consumer, which only escape can satisfy (Engag et al., 2020).

Today, it is obvious that no economic or health crisis can stop tourist activity forever. In the extreme case, the development of macabre tourism (or obscure tourism) testifies how tourism can deal with the fear of tourists and tame it.

Thus, the COVID-19 epidemic could alter the behavior of tourism demand in a way that risks will be an intrinsic part of the tourism experience.

In addition, several types of tourism meet unavoidable needs, for example, business tourism, very strongly affected by the health crisis, seems to be incompressible because it meets economic needs more than leisure. 


\section{Method}

To forecast one scenario over another or to describe a mixture between them, we suggested the use of the Delphi method. The goal of this technique is to ensure a convergence of opinions on forward-looking issues, such as demand for sustainable tourism (Choi \& Sirakaya, 2006) and predictions on tourist destination (Lee \& Hsieh, 2016; Miller, 2001; Torres-Delgado \& Palomeque, 2014).

Thus, the Delphi survey takes place in a variety of rounds, taking into account the convergence opinions of a confirmed tourism expert panel, namely provincial tourism delegates, representatives of tourism organizations, experts in sustainable tourism, researchers in tourism, etc.

Several tourism studies have used the Delphi method to create sustainable tourism metrics, to design a tourism offer or to make tourism demand forecasts. The following table provides examples of the Delphi method applications in the tourism field.

Table 1. Examples of the Delphi Method application on Tourism

\begin{tabular}{|l|l|l|}
\hline \multicolumn{1}{|c|}{ Authors } & \multicolumn{1}{|c|}{ Main objective } & \multicolumn{1}{c|}{ Study zone } \\
\hline (Thanh, 2014) & Forecast tourism demand & Vietnam \\
\hline (Arnandis-I-Agramunt, 2019) & Design of a tourism resource & Spain \\
\hline (Miller, 2001) & $\begin{array}{l}\text { Construction of sustainable tourism } \\
\text { indicators }\end{array}$ & $\begin{array}{l}\text { United } \\
\text { Kingdom }\end{array}$ \\
\hline (Choi \& Sirakaya, 2006) & $\begin{array}{l}\text { Construction of sustainable tourism } \\
\text { indicators }\end{array}$ & Canada \\
\hline (Lee \& Hsieh, 2016) & $\begin{array}{l}\text { Construction of sustainable tourism } \\
\text { indicators }\end{array}$ & Taiwan \\
\hline $\begin{array}{l}\text { (Torres-Delgado \& Palomeque, } \\
\text { 2014) }\end{array}$ & $\begin{array}{l}\text { Construction of sustainable tourism } \\
\text { indicators }\end{array}$ & $\begin{array}{l}\text { Catalonia } \\
\text { (Spain) }\end{array}$ \\
\hline
\end{tabular}

Source: by authors

At the practical level, the Delphi survey takes place in several steps, first of all, it is necessary to define the survey problem, to select experts and secondly, to develop a questionnaire and its administration.

\subsection{Delphi Survey Research Problem}

Foremost, each survey must define its research problem. In our case, it consists in prevailing a scenario of tourism development after and during the COVID-19 health crisis.

Moreover, this research problem and its objective must be clearly communicated to the chosen experts in order to avoid any ambiguity and to be able to orient the reflection on to the main subject study (Questionnaire cover letter and preamble).

\subsection{Selection of Delphi Survey Experts}

The selection of experts is the most sensitive step in the Delphi method. It is questionable because of the subjectivity that can be introduced when choosing experts and their qualification. To this end, we referred to several studies in order to circumvent the qualifying conditions of an expert (Choi \& Sirakaya, 2006; Torres-Delgado \& Palomeque, 2014).

Therefore, an expert can be considered as a "person whose profession is to assess the value of something" (Miller, 2001, p. 3). This definition emerges from the two criteria retained for the selection of experts. First, to have a permanent and habitual contact with the subject studied, by profession or interest, and secondly, to have the proven ability to assess the value of the object studied, justified by scientific publications for academics or the exercise of decision-making or consultation power for others.

Moreover, the experts must remain anonymous in order to neutralize mutual influences and to guarantee the results' reliability. Several researchers propose this condition, in order to avoid a conformism consensus among experts (Choi \& Sirakaya, 2006; Torres-Delgado \& Palomeque, 2014).

To this end, at the start, we contacted 22 experts, but only 19 expressed interest in participating in the survey. This number is close to 18 recommended for carrying out a Delphi survey (ArnandisI-Agramunt, 2019; Miller, 2001). Moreover, Delphi method it is different to an opinion survey that 
depends on the sampling rules; but the findings validity depends exclusively on the knowledge, skill and intentional cooperation of the consulted experts.

\subsection{Questionnaire Administration and Consensus Validation}

The Delphi survey takes place in two steps, called "rounds" which help to achieve a consensus on the fundamental aspects of the Post-Covid tourism scenario. To do so, we have conducted the questionnaire by email or face to face, depending on the availability of the interviewed expert.

Therefore, we have carried out an initial survey of all the experts selected for this report. Once this first step has been completed, we have again administered the same questionnaire to the same experts, but in this time, we have presented the first step findings.

During second panel, experts take an idea about the effects of the other experts' reactions anonymously. In the second step, experts can either retain their answers or decide, otherwise, to settle on a consensus opinion. In addition, in order to evaluate the consensus degree of this process, we plan to adopt the Isaak (1996) and Zenou (2004) methods.

Therefore, the consensus validation relies mainly on concordance and convergence parameters. For this purpose, the Kendall criterion makes it possible to calculate the results consensus degree of the panel, from the threshold of confidence. It allows calculating the concordance of the experts' answers during a round.

In addition, the Wilcoxon test (Schmidt, 1997) allows the integration of responses between the two panels to infer if there is a consensus on the under investigation phenomenon.

\subsection{Validation of the expert opinions concordance}

Thus, in the light of the obtained results, we observed an improvement in the Kendall index " $w$ " which becomes closer to a strong consensus $(W=0.7)$, which shows the experts convergence around proposed items. The table below shows the results of the Kendall concordance test during the two survey phases.

Table 2. Results of the Kendall Concordance Test

\begin{tabular}{|c|c|c|}
\hline $\begin{array}{l}\text { Kendall concordance } \\
\text { test }\end{array}$ & Round 1 & Round 2 \\
\hline $\mathrm{N}$ & 19 & 19 \\
\hline Kendall W & 0,565 & 0,691 \\
\hline chi-square & 688,266 & 907,965 \\
\hline Asymptotic value & 0,000 & 0,000 \\
\hline
\end{tabular}

In addition, the improvement of Kendal index, from one round to another, shows that the answers converge towards a consensus among the experts. Therefore, we decided to obtain a consensus around the fundamental aspects of Post-COVID tourism.

\subsection{Validation of Expert Convergence}

Moreover, to validate the consensus between experts, Schmidt (1997) also proposes to carry out a non-parametric statistical test to measure the responses' distribution about items, during the two phases. This is the Wilcoxon test (signed ranks) to measure the convergence degree between the two panels during the two rounds.

This method consists in testing two hypotheses:

- H0: Distribution of Mean Absolute Deviation (MAD) is similar between the two panels.

- H1: Distribution of MAD in the second round is lower than the first round (MAD2 <MAD1; convergence of responses).

For this purpose, if $\mathrm{H} 1$ is significantly validated with a high degree of confidence (asymptotic significance $=0.000<1 \%$ ). Thus, the answers converge between the two rounds of the survey. The table below shows the Wilcoxon test finding, during the two rounds of the survey. 
Kamar F., Charrass A. E Bahyaoui S. (2020). Post-covid tourism, a consensual re-reading of the economic outlook application of the delphi method to "morocco" destination. The Journal of International Scientific Researches, 5(AI), 15-21.

\section{Table 3. Wilcoxon Test Results}

\begin{tabular}{|c|c|c|c|c|}
\hline \multicolumn{2}{|c|}{ Rangs } & $\mathrm{N}$ & $\begin{array}{c}\text { Average } \\
\text { rank }\end{array}$ & Sum of ranks \\
\hline \multirow{4}{*}{$\begin{array}{l}\text { MAD_ROUND2 - } \\
\text { MAD_ROUND1 }\end{array}$} & Negative ranks & $6 a$ & 4.7 & 66,00 \\
\hline & Positive ranks & $9 \mathrm{~b}$ & 8.3 & 30,00 \\
\hline & Ex aequo & 0c & & \\
\hline & Total & 15 & & \\
\hline \multicolumn{5}{|c|}{ a. MAD_ROUND2 < MAD_ROUND1 } \\
\hline \multicolumn{5}{|c|}{ b. MAD_ROUND2 > MAD_ROUND1 } \\
\hline \multicolumn{5}{|c|}{ c. MAD_ROUND2 = MAD_ROUND1 } \\
\hline \multicolumn{2}{|c|}{ Statistical tests } & \multicolumn{3}{|c|}{ MAD_ROUND2 - MAD_ROUND1 } \\
\hline \multicolumn{2}{|l|}{ Z } & \multicolumn{3}{|c|}{$-5,452 b$} \\
\hline \multicolumn{2}{|c|}{ Sig. asymptotic (bilateral) } & \multicolumn{3}{|c|}{0,000} \\
\hline \multicolumn{5}{|c|}{ a. Wilcoxon ranking test; b. Based on positive ranks. } \\
\hline
\end{tabular}

Source: Calculated by the authors, using SPSS (V25)

To this end, we have obtained a convergence of opinions on nine aspects of the scenarios and a rejection of six non-consensual aspects. The elements comprising the most common scenario are presented below.

2.6. Determination of the consensual scenario.

Thus, after having demonstrated the responses' convergence between the experts in the two rounds, and in the light of the results obtained, we proceeded to the selection of the post-Covid tourism aspects.

Table 4. Consensus on a Post-COVID Tourism Scenario (Based on Delphi Method Results)

\begin{tabular}{|c|c|c|}
\hline & Scenario Component & (MAD2-MAD1) \\
\hline 1 & COVID epidemic affects tourism demand behaviors & $-0,5250$ \\
\hline 2 & Tourists adapt to health requirements and travel anyway. & $-0,1500$ \\
\hline 3 & Tourists from international destinations choose to visit local destinations & $-0,2083$ \\
\hline 4 & Domestic tourism offers the best outlook for a revival of the tourism sector. & $-0,5233$ \\
\hline 5 & As a precaution, post-COVID tourism will be a local tourism & 0,0017 \\
\hline 6 & $\begin{array}{l}\text { Rural and isolated destinations and natural spaces could attract visitors } \\
\text { previously interested in foreign destinations. }\end{array}$ & $-0,3750$ \\
\hline 7 & $\begin{array}{l}\text { Evolution of tourism demand is dependent on the epidemic evolution in the } \\
\text { medium run. }\end{array}$ & $-0,2083$ \\
\hline 8 & $\begin{array}{c}\text { Evolution of tourism demand is dependent on the epidemic evolution in the long } \\
\text { run. }\end{array}$ & 0,2083 \\
\hline 9 & $\begin{array}{l}\text { Tourist activity will resume its rhythm and will stand out from the epidemic } \\
\text { evolution. }\end{array}$ & 0,2500 \\
\hline 10 & $\begin{array}{l}\text { In the long term, considering the health circumstances, tourism will resume its } \\
\text { development. }\end{array}$ & 0,2917 \\
\hline 11 & Post-COVID tourism will experience an unprecedented revival. & 0,8548 \\
\hline 12 & Post-COVID tourism will evolve at a slow pace. & 0,5214 \\
\hline 13 & Post-COVID tourism will cancel part of the initial demand & 0,3256 \\
\hline 14 & Post-COVID tourism will accumulate part of the initial latent demand & 0,4251 \\
\hline 15 & tourism demand will not change behaviors on Post COVID period & 0.6123 \\
\hline
\end{tabular}

Source: Calculated by the authors, using SPSS (V25) 
According to previous results, experts are convergent on the COVID epidemic effects on tourism demand behaviors; they confirm that it depends on the epidemic evolution in the medium run. In the same logic, recent literature confirms that tourism will grow in line with the disease situation; during and after the COVID crisis (Blanc, 2020).

Thus, the findings of the Delphi study are dominated by the medium-term "Stop and Go" scenario. In this context, the growth of tourism would be a mixture of release periods, followed by restricting periods.

However, in the long run, tourists will be able to adapt themselves to the health requirements, and they will travel anyway, despite the epidemic situation. This forecast is in line with the third scenario that foresees the resumption of tourist activity in all circumstances.

Moreover, in the short term, tourism converts to domestic and local tourism. In this logic, the experts agree that tourists from international destinations choose to visit local destinations. This result supports several observations in the literature that consider domestic tourism offers such as the best outlook for a revival of the tourism sector (Mishra et al., 2020; Zenker \& Kock, 2020).

In this sense, the Delphi method findings confirm the second scenario of domestic tourism in the short run. Thus, rural and isolated destinations and natural spaces could attract visitors previously interested in foreign destinations.

\section{Results and Discussion}

Following our Delphi survey process, we performed an initial survey of all the experts selected for the study. When this first survey was carried out, we began the same survey again with the same experts, but we submitted to them the first survey findings.

During this second round, each expert consulted anonymously how the other experts had answered the same questionnaire. As a result, they had a choice between sticking to their answer and deciding to move closer to the general view.

To this end, we carried out two rounds of surveys to reach a consensus on the most relevant aspects of the proposed scenarios. Moreover, data of Delphi study were entered and analyzed, by using SPSS software (version 25.0).

\section{Conclusion}

Moroccan tourism is already suffering from the health crisis and the perspectives are more blurred; which increases uncertainty and affects the various stakeholders' actions in a tourist destination. At a time of deconfinement, several questions are asked about the future of tourist demand.

Therefore, it is important to challenge tourism experts on the tourism market future and to give priority to the post-COVID tourism scenario. Thus, we used the DELPHI method, which is very useful in the case of prospective studies that suffer from uncommon literature, such as the unprecedented outbreak of COVID-19.

The results of the expert consultation demonstrate the importance of distinguishing between three demand behaviors, separated along the time axis.

In the short term, the tourism market will be directed towards local tourism; the tourist will take the car instead of the plane and walk instead of the car. In this context, visitors are going to visit the natural parks and the nearby restaurants.

However, the findings confirm the prevalence of the "Stop and GO" scenario over the medium term. In this logic, the visitors' actions would closely follow the disease situation in order to determine whether to escape or stay at home or nearby.

Finally, no strength is able to avoid the urgent need to get away in the long run; the results indicate that tourism Post-Covid, tourism can find new ways of traveling and internalize the health risk.

Ultimately, this paper faces limitations related the forward-looking exercise, on a very volatile and changing topic, such as tourism and the COVID-19 health crisis. Moreover, during the experts' 
selection, a part of subjectivity could be introduced. In the end, it is not a question of eliminating subjectivity, but using it wisely to understand our research subject (Drapeau, 2009).

\section{References}

Arnandis-I-Agramunt, R. (2019). What's a tourism resource? A Delphi analysis to the Hispanic academia. Cuadernos de Turismo, 43, 553-555. https://doi.org/10.6018/turismo.43.02

Blanc, J.-M. (2020). Sommaire. Futuribles International, 1(1), 1-20.

Choi, H. C., \& Sirakaya, E. (2006). Sustainability indicators for managing community tourism. Tourism Management, 27(6), 1274-1289. https:/ / doi.org/10.1016/j.tourman.2005.05.018

Duarte Alonso, A., Kok, S. K., Bressan, A., O’Shea, M., Sakellarios, N., Koresis, A., Buitrago Solis, M. A., \& Santoni, L. J. (2020). COVID-19, aftermath, impacts, and hospitality firms: An international perspective. International Journal of Hospitality Management, 91(June), 102654. https://doi.org/10.1016/j.ijhm.2020.102654

Engag, L. E. S. A., Dans, E. S., Domaine, L. E., Tourisme, D. U., \& Au, F. (2020). Les actions engagées dans le domaine du tourisme face au coronavirus ( COVID-19). 1-78.

Kock, F., Nørfelt, A., Josiassen, A., Assaf, A. G., \& Tsionas, M. G. (2020). Understanding the COVID19 tourist psyche: The Evolutionary Tourism Paradigm. Annals of Tourism Research, 85(September), 103053. https:// doi.org/10.1016/j.annals.2020.103053

Lee, T. H., \& Hsieh, H.-P. (2016). Indicators of sustainable tourism: A case study from a Taiwan's wetland. Ecological Indicators, 67, 779-787. https:// doi.org/10.1016/j.ecolind.2016.03.023

Miller, G. a. (2001). The Development of Indicators for the Promotion of Sustainable Tourism. 22, 351-362. http:/ / epubs.surrey.ac.uk/theses/133

Mishra, N. P., Das, S. S., Yadav, S., Khan, W., Afzal, M., Alarifi, A., kenawy, E.-R., Ansari, M. T., Hasnain, M. S., \& Nayak, A. K. (2020). Global impacts of pre- and post-COVID-19 pandemic: Focus on socio-economic consequences. Sensors International, 1(September), 100042. https://doi.org/10.1016/j.sintl.2020.100042

Thanh, V. T. (2014). Prévision de la demande touristique par méthodes Delphi et Box-Jenkins. Téoros: Revue de Recherche En Tourisme, 29(1), 100. https:/ / doi.org/10.7202/1024760ar

Torres-Delgado, A., \& Palomeque, F. L. (2014). Measuring sustainable tourism at the municipal level. Annals of Tourism Research, 49, 122-137. https://doi.org/10.1016/j.annals.2014.09.003

Zenker, S., \& Kock, F. (2020). The coronavirus pandemic - A critical discussion of a tourism research $\begin{array}{llll}\text { agenda. Tourism } & \text { Management, } & \text { 81(June), }\end{array}$ https://doi.org/10.1016/j.tourman.2020.104164. 